\title{
Utility of crime surveys for Sustainable Development Goals monitoring and violence prevention using a public health approach
}

\author{
R Matzopoulos,${ }^{1,2} \mathrm{PhD} ; \mathbf{N}$ Abrahams, ${ }^{3} \mathrm{PhD}$; B Bowman, ${ }^{4} \mathrm{PhD} ; \mathbf{N}$ Shai, ${ }^{3} \mathrm{PhD} ;$ M Prinsloo, ${ }^{1} \mathrm{MPH}$; S Salau, ${ }^{5} \mathrm{MSc} ; \mathrm{D}$ Bradshaw, $\mathrm{PhD}$; \\ G Gray, ${ }^{6} \mathrm{MB}$ BCh, FCPaeds (SA), DSc (honoris causa) \\ ${ }^{1}$ Burden of Disease Research Unit, South African Medical Research Council, Cape Town, South Africa \\ ${ }^{2}$ School of Public Health and Family Medicine, Faculty of Health Sciences, University of Cape Town, South Africa \\ ${ }^{3}$ Gender and Health Research Unit, South African Medical Research Council, Cape Town, South Africa \\ ${ }^{4}$ School of Human and Community Development, Faculty of Health Sciences, University of the Witwatersrand, Johannesburg, South Africa \\ ${ }^{5}$ Department of Statistical Sciences, Faculty of Science, University of Cape Town, South Africa \\ ${ }^{6}$ Office of the President, South African Medical Research Council, Cape Town, South Africa
}

Corresponding author: R Matzopoulos (richard.matzopoulos@uct.ac.za)

\begin{abstract}
The Sustainable Development Goals (SDGs) have highlighted interpersonal violence and violence against women and girls as impediments to development globally. South Africa is adversely affected by violence and injury. The annual Victims of Crime Survey (VoCS) provides a potentially useful source of complementary data to bolster vital registration and police crime statistics, but it may not provide data that are sufficiently accurate and reliable to inform prevention efforts. We conducted a critical assessment of the VoCS's methodological robustness and strength as a data source for high-level analyses, adopting a public health and SDGs monitoring perspective that was based on expert opinion and comparison with other data sources. We concluded that either the survey methods should be improved to provide findings that are better aligned with the SDGs agenda and are robust enough to inform high-quality research and prevention, or the funds used to conduct the VoCS should be redirected to other more suitable instruments.
\end{abstract}

S Afr Med J 2019;109(6):382-386. DOI:10.7196/SAMJ.2019.v109i6.13806

Violent crime continues to impose a considerable health and economic burden on the population of South Africa (SA), ${ }^{[1]}$ which has among the world's highest homicide rates and one of the world's highest rates of gender-based violence, including intimate femicide, ${ }^{[2,3]}$ rape $^{[4,5]}$ and intimate partner violence. ${ }^{[5-7]}$ Violence prevention policies have previously focused on violence against women and children, both globally and in SA ${ }^{[8.9]}$ Now the Sustainable Development Goals (SDGs), which outline an ambitious agenda for international development, have substantially extended the violence prevention ambit of previous instruments. SDG 5 builds on the third Millennium Development Goal in seeking to secure gender equality and empowerment of women and girls, and now includes specific targets to eliminate violence against women and girls. In addition, SDG 16, which promotes peace, justice and strong institutions, has called for the reduction of 'all forms of violence everywhere' (target 16.1), which implicitly includes men in the violence prevention ambit. ${ }^{[10]}$ In responding to this challenge, it is imperative that prevention efforts are evidence based and monitored using measures that provide sufficient detail and are derived from reliable and accurate information sources. In SA even routine administrative data on homicide, widely considered the most robust measure for national rates of violence, are not always reliable. Police statistics are considered to under-report homicide, ${ }^{[11]}$ and vital registration data based on death registration are beset with misclassification. ${ }^{[12]}$

In addition, Statistics South Africa (Stats SA) publishes an annual Victims of Crime Survey (VoCS), the most recent of which, for 2017/18, was released on 11 October 2018. The United Nations Office on Drugs and Crime considers the VoCS to be an important tool for the comparison of risks across countries and world regions, and there is therefore merit in reviewing the utility of the VoCS data more broadly as a potential source of complementary data on violence in SA. ${ }^{[13]}$ In this brief review we assess such utility from a public health and SDGs monitoring perspective, considering its methodological strengths and weaknesses in comparison with other sources, including routine official data such as police crime statistics and vital registration, as well as surveys and other research data.

\section{The crime and violence prevention agenda: VoCS data in context}

The first SA VoCS was conducted by Stats SA in $1998,{ }^{[14]}$ and the Institute for Security Studies co-ordinated a repeat survey in $2003,{ }^{[15]}$ consistent with the international crime victims surveys that were initiated by European criminologists in the late 1980s. ${ }^{[16]}$ Stats SA began annual VoCS reporting based on this formative work from 2010 onwards.

The 2017/18 VoCS report describes three main objectives: providing information about the dynamics of crime from the perspective of households and the victims of crime; exploring public perceptions of the activities of the police and criminal justice systems in the prevention of crime and victimisation; and providing complementary data on the level of crime in SA in addition to the statistics published annually by the SA Police Service. ${ }^{\text {[17] }}$ These objectives fit most comfortably within the ambit of SDG 16, which focuses on the promotion of peaceful and inclusive societies for sustainable development, the provision of access to justice for all, and building effective, accountable institutions at all levels, and - with 
regard to violence against women and female children - SDG 5, which strives to achieve gender equality and empower women and girls (Table 1). At face value, the first of SDG 16's 12 targets, 'significantly reduce all forms of violence and related death rates everywhere', is most applicable to the data collected in the VoCS, which collects information on homicide. SDG 16 target 6, 'Develop effective, accountable and transparent institutions at all levels', is also relevant in that the VoCS describes attitudes towards the police, as are SDG 5 targets 2 and 3, which call for the elimination of all violence and harmful practices against women and girls. Finally, we consider the alignment of data sources for public dissemination encompassed in SDG 16 target 10, which endorses public access to information, as providing an additional impetus for this review.

While the SDGs focus on violence is not particularly compatible with the crime and victimisation lens of the VoCS, it does resonate with a public health-based measurement perspective. Here, notwithstanding the invidious psychosocial and socioeconomic effects of crime on development, specific crime categories of interest are those that relate directly to various forms of interpersonal violence, namely murder (i.e. homicide), assault, sexual offences and various forms of robbery (e.g. home robbery, vehicle hijacking). These crime categories, by definition, involve interpersonal interaction between victim and perpetrator, with the actual or threatened likelihood of violence. Conceptualising these crimes in this way is consistent with the public health approach to violence prevention because they manifest in harms that are measurable from sources beyond just the criminal justice system and are quantifiable through burden of disease estimation. Drawing on expert opinion and various existing sources, we therefore assessed the utility of the data collected and reported by the VoCS as additional measures of the burden of violence to inform prevention programming.

\section{Adequacy of VoCS data in describing major crime categories \\ Homicide}

Homicide data are generally considered the most accurate measure of violence ${ }^{[18]}$ Although there is some indication of under-reporting of homicide in police data - the 2009 police murder statistics described $12 \%$ fewer homicides than were recorded in forensic pathology laboratories ${ }^{[11]}$ - the data are considerably more accurate than other categories of severe contact crime such as rape, where only one in 13 women are likely to report cases to the police. ${ }^{[7]}$ The VoCS does not provide reliable homicide estimates overall, or for women specifically.

\section{Table 1. SDGs 5 and 16 and their respective targets}

\section{Goal 5: Achieve gender equality and empower all women and girls}

1. End all forms of discrimination against all women and girls everywhere

2. Eliminate all forms of violence against all women and girls in the public and private spheres, including trafficking and sexual and other types of exploitation

3. Eliminate all harmful practices, such as child, early and forced marriage and female genital mutilation

4. Recognise and value unpaid care and domestic work through the provision of public services, infrastructure and social protection policies and the promotion of shared responsibility within the household and the family as nationally appropriate

5. Ensure women's full and effective participation and equal opportunities for leadership at all levels of decision making in political, economic and public life

6. Ensure universal access to sexual and reproductive health and reproductive rights as agreed in accordance with the Programme of Action of the International Conference on Population and Development and the Beijing Platform for Action and the outcome documents of their review conferences

7. Undertake reforms to give women equal rights to economic resources, as well as access to ownership and control over land and other forms of property, financial services, inheritance and natural resources, in accordance with national laws

8. Enhance the use of enabling technology, in particular information and communications technology, to promote the empowerment of women

9. Adopt and strengthen sound policies and enforceable legislation for the promotion of gender equality and the empowerment of all women and girls at all levels

Goal 16: Promote just, peaceful and inclusive societies

1. Significantly reduce all forms of violence and related death rates everywhere

2. End abuse, exploitation, trafficking and all forms of violence against and torture of children

3. Promote the rule of law at the national and international levels and ensure equal access to justice for all

4. By 2030, significantly reduce illicit financial and arms flows, strengthen the recovery and return of stolen assets and combat all forms of organised crime

5. Substantially reduce corruption and bribery in all their forms

6. Develop effective, accountable and transparent institutions at all levels

7. Ensure responsive, inclusive, participatory and representative decision-making at all levels

8. Broaden and strengthen the participation of developing countries in the institutions of global governance

9. By 2030, provide legal identity for all, including birth registration

10. Ensure public access to information and protect fundamental freedoms, in accordance with national legislation and international agreements 11. Strengthen relevant national institutions, including through international co-operation, for building capacity at all levels, in particular in developing countries, to prevent violence and combat terrorism and crime

12. Promote and enforce non-discriminatory laws and policies for sustainable development 
The VoCS estimated 16809 murders in the 2017/18 reporting period, 12 - 17\% lower than the 19016 and 20336 reported by the police in $2016 / 17$ and $2017 / 18$, respectively. There was also considerable variance in the year-on-year murder trend reported in the VoCS, with a recorded peak of 26529 murders in 2013/14 - almost 60\% higher than police figures for the corresponding period. Year-onyear comparison of the VoCS data suggests a decline in the murder rate of $37 \%$ over the 5 -year period from $2013 / 14$ to $2017 / 18$. This contradicts police statistics, which showed a gradual increase over this period. ${ }^{[19]}$ It is unlikely that there would be sufficient annual variation to explain the discrepancy between the police and VoCS data. It is more likely that the discrepancy arises from the small number of cases from which the VoCS estimates were derived - for example, just 25 cases in 2016/17.

A thematic report based on previous VoCSs was also recently in the media spotlight following a special release that claimed an extraordinary $117 \%$ increase in female homicide in a single year. ${ }^{[20]}$ The finding was based on a comparison of 20.8 per 100000 in 2016/17 with a 2015 World Health Organization (WHO) female homicide rate estimate of 9.6 per 100000 population, ${ }^{[2]}$ but it could not be corroborated by other data sources and seemed implausible. It is not good practice to derive a trend based on different data sources that used different methodologies, and the use of the WHO estimate as a comparator to the VoCS estimate represented an improbable $117 \%$ increase in female homicide in a single year. The WHO had reported a consistently declining female homicide trend from a high of 21.4 per 100000 population in 2000 . The trend and the level of female homicide rates are consistent with the second National Burden of Disease Study ${ }^{[1]}$ and a representative national study of female homicide with sampling in 1999 and 2009. ${ }^{[2]}$

\section{Assault}

Although considered a less reliable measure than homicide, comparison of the VoCS estimates for assault with cases arising from police statistics is more favourable. The VoCS reported 355739 or $4 \%$ fewer assaults than the total of 341828 reported by the police in $2017 / 18$, i.e. by combining the three major police categories for nonfatal assault: attempted murder, common assault and assault with the intent to cause grievous bodily harm. ${ }^{[2]}$ The VoCS estimate suggests an overall assault rate of 635 per 100000 population.

This figure is considerably higher than figures that have been reported in the South Africa Demographic and Health Survey (SADHS). The latest SADHS for $2016^{[23]}$ was the third to be conducted in SA in collaboration with the worldwide Demographic and Health Surveys Program following earlier studies for 1998 and 2003. However, the 2016 SADHS focused on violence against women and did not record overall rates of violence. In 2003, the overall intentional injury rates (i.e. violence) among men and women were estimated at 370 and 225 per 100000 , respectively. ${ }^{[24]}$ This was at a time when SA's homicide rates were considerably higher than they are currently. One reason for the lower SADHS estimates is that the questionnaire refers specifically to injuries severe enough to require medical attention. This severity threshold is not applicable to either the police data or the VoCS estimates.

\section{Robbery}

The VoCS classifies robberies into vehicle hijackings, robberies outside the home, and residential robberies. The police divide robbery into common robbery and robbery with aggravating circumstances (these include the 'trio' crimes car/truck hijackings, residential robbery and business robbery, and public/street robberies with a weapon). Contrasting the VoCS robbery estimates with police data is complicated because only vehicle hijackings and home robberies are comparable categories. In both cases there are significant variations in reporting trends. While 34880 vehicle hijackings were recorded in the 2017/18 VoCS, only 17527 such cases were reported by the police over the same period (the figure of 17527 was calculated by summing the 16325 cars and 1202 trucks reported as hijacked in the South African Police Service 2016/17 data). ${ }^{[22]}$ This difference is more pronounced when comparing the VoCS and police house robberies. The 2017/18 VoCS reported 156089 incidents of home robbery - more than seven times the 22261 cases reported by the police. Such under-reporting has been shown to be related to the economic consequences of the robbery (e.g. insurance requirements) and attitudes to local policing. ${ }^{[25,26]}$

In addition to these discrepancies, other forms of violence that occur alongside robberies are not directly linked to robbery in the VoCS. This limitation is significant given that a recent study using police data showed that $3.9 \%$ of all robberies reported to the police between 2004 and 2014 progressed beyond the threat of force to a crime resulting in injury. ${ }^{[27]}$ This proportion should therefore be reported in the VoCS in future to more accurately describe the features of this important situational context for violence. The value of doing so is already evident in specific cases where comparator categories are well aligned to other data sources. For example, a stand-alone study of home robberies by Stats SA drawing on VoCS data from 2010/11 provides important contextual detail on risk factors for injury that can be used alongside existing police data for crime-specific prevention. ${ }^{[28]}$ When the VoCS is subject to such 'in-depth' analysis, it is among the only sources of information on perpetrators of robbery, which is missing in $77 \%$ of police cases. ${ }^{[27]}$ Albeit that this information is reported by victims, these data nonetheless contribute to a fuller understanding of robberies, which constitute a significant share of violence in SA.

\section{Sexual offences}

The 2017/18 VoCS estimated that there were 28596 sexual offences (described as rape, grabbing or touching without consent) - just over half of the 50108 cases reported to the police in 2017/18. Police data are based on reported crimes, and sexual violence by an intimate partner is most often not reported. ${ }^{[4,5]}$ Crime statistics do not provide specific crime categories for domestic violence, and neither do police publish data recorded in the Domestic Violence Register. Consequently, both VoCS and police data on sexual offences may be more reflective of women's access to the criminal justice system. ${ }^{[7]}$

The lower level of reporting in the current VoCS is in stark contrast to the previous period, which reported $40 \%$ more cases than the police. ${ }^{[29]}$ Moreover, it is not clear whether the lower estimates now provide a realistic measure of sexual offences directed at women or one that is also affected by under-reporting. SADHS findings from a special module on domestic violence reported that among the ever-partnered women aged 18 - 49 years, $6.2 \%$ had experienced sexual violence by a partner and $2.9 \%$ had experienced sexual violence during the 12 months preceding the survey. ${ }^{[23]}$ Even so, comparison with provincial population studies indicates that the SADHS underestimates partner violence - in a Gauteng study, $18.9 \%$ of the women reported experiencing partner rape and $18.2 \%$ of the men reported partner rape perpetration. ${ }^{[5]}$

\section{Perceptions}

The VoCS reports extensively on perceptions of crime, including perceptions of crime trends (invariably perceived to be increasing), feelings of safety (substantially lower after dark), beliefs about reasons 
for committing crime (predominantly attributed to drugs, but oddly omitting alcohol), and attitudes related to women and gender-based violence (considered generally, but not consistently, unacceptable). It is not clear how reflective these reported perceptions are of actual attitudes or subsequent behaviour. However, the VoCS does include questions about respondents' attitudes towards the police, the courts and the correctional services. These provide information relevant to SDG 16 target 6 , which relates to effective, accountable and transparent institutions. These measures are valuable, as we are not aware of any other sources of routine data for SA that provide comparable information.

\section{Methodological strengths and wealnnesses}

One of the methodological strengths of the VoCS is its use of the Stats SA master sample, a sample drawn from the SA population for use across multiple surveys and over an extended period to avoid $a d$ hoc sampling for each survey. There are two advantages to this. First, notwithstanding variability in fieldwork from year to year, the use of a consistent sampling frame should ensure consistency with previous VoCS waves, enabling comparisons over time. Second, the master sample is used by other Stats SA household surveys, such as the General Household survey, which enables the inclusion of additional variables for complementary analyses. However, to provide a nationally representative sample that allows for more granular smallarea analyses, Stats SA is currently changing its sampling frame, i.e. the list of all structures (households and institutions) from which its samples are drawn. As with other surveys, the VoCS will either need to adapt to the new sampling frame and forego its trend analyses, or maintain its use of the earlier sampling method and lose some of its compatibility with other Stats SA surveys.

There are also methodological weaknesses in the VoCS that need to be addressed to strengthen its utility for violence prevention and SDGs monitoring.

\section{Terminology}

Definitions should be guided by evidence and have no ambiguity, which applies equally to terminology for statistics relating to interpersonal violence. This is challenging and evolving, and even within the limited scope of this short review, we noted several inconsistencies. The International Statistical Classification of Diseases and Related Health Problems, 10th revision (ICD-10) and ICD-11 systems refer to the external cause of injury and death as 'assault' and include extension codes for different contexts and mechanisms. The burden of disease and violence research communities frequently combine these categories under an 'interpersonal violence' banner, and fatal events are described as 'homicide. The term 'murder' does not appear in health classifications. It may be a suitable term for a survey questionnaire on crime, as the public has a general understanding of the term, but it has a specific meaning in criminology and crime statistics involving premeditation. Furthermore, the latest VoCS combines police murder statistics with culpable homicides - a category that includes road traffic fatalities.

The VoCS Crime Against Women report ${ }^{[20]}$ included definitions for 'femicide' and 'intimate femicide' - both forms of gender-based violence directed at straight, lesbian, bisexual or transgender women/ girls because of gender - but on occasion conflates these categories with female homicide.

\section{Sample size and data quality}

The effects of the small sample size on violent crime categories, importantly the relatively rare events, have already been noted and are at odds with the SDG's 'leave no one behind' principle. The VoCS report does provide a 'quality flag' based on the coefficient of variation $(\mathrm{CV})$, a measure of the relative size of error for each statistic. However, in the case of murder the CVs for females and males were $32 \%$ and $35 \%$, respectively. By the data quality standards outlined in the report, these were described as 'acceptable statistics', but with the caveat that they be treated with caution. For the overall number of murders the CV of $24 \%$ denotes a 'quality statistic'. This may be true statistically, but does not tally with a public health monitoring perspective as the VoCS data compared poorly with other sources. In addition, we note that quality caveats were not reflected adequately in the report - poor-quality statistics were featured prominently in the executive summary - and the media were not adequately apprised of these limitations.

\section{Data collection tools and fieldwork}

There are standardised measures for collecting reliable information on violence against women from surveys. These have been used in multiple studies over the past $\sim 15$ years and have established validity and reliability. Fieldwork methods that ensure safety and confidentiality are also vital.

Questions on sexual violence are sensitive, and their place and sequence in the questionnaire, alongside terminology and fieldworker profiles and training, need to be considered to optimise disclosure. ${ }^{[30,31]}$ Questions on rape and sexual assault should be preceded by gender sensitisation training for interviewers to enhance understanding of the concepts and the responses proffered by participants and to limit the effects of discomfort in asking sensitive questions. Moreover, the ethics of conducting research on sensitive issues needs to be considered. For example, is the respondent alone when they are asked about experiences of rape/sexual assault and even other sexual offences, or fearful of being overheard? The environment has a bearing on the ability to respond. Stats SA officials recognised that these issues cannot easily be addressed in the VoCS, ${ }^{[32]}$ possibly owing to the scope and limited budget. However, Stats SA's 2016 DHS conducted in collaboration with the South African Medical Research Council (SAMRC) included an improved module on violence against women that drew on experts to guide the development of research questions and to oversee fieldworker training. It is these aspects that may have realised higher disclosure rates and therefore higher estimates of violence against women in the domestic setting.

\section{Conclusions}

We have identified several data sources that can provide more reliable measures of interpersonal violence than the VoCS for SDG monitoring and prevention using a public health approach. For murder, police statistics are likely to provide a more reliable measure, especially if validated by intermittent mortuary-based injury mortality surveys. Police crime data provide similar estimates to the VoCS for assault, and the SADHS provides estimates for serious cases requiring medical treatment. For sexual offences, the more nuanced data collection methods applied by the SADHS allow for the collection of more reliable data, but reliable estimates might only be achieved through a dedicated national study on violence against women.

Where the VoCS has added value is in providing robbery estimates that far exceed cases reported by the police and in providing a unique perspective of policing, the courts and correctional services. Even so, these measures alone may not be sufficient to justify the expense of maintaining the VoCS as a routine survey. Instead, funds might be better spent by regularising the collection of data from other surveys. Indeed, the underestimate of intimate partner violence in the current 
SADHS points to the need for funding of dedicated surveys on injury mortality and violence against women. Another approach would be to consider appending selected modules to other routine surveys such as the General Household Survey. We also note with concern that at a global level interest in victimisation surveys has waned, with the latest International Crime Victimisation Survey reflecting data for 2005. ${ }^{[16]}$

As researchers we appreciate Stats SA's expenditure and effort in conducting the VoCS. However, we would like to emphasise the need for greater policy coherence to address violence in society more broadly aligned with SDG 5 and SDG 16 . Accurate statistics will be crucial for policy development and monitoring. As it stands, the VoCS offers very limited information to inform SDG monitoring or a public health prevention response. The SAMRC and its associates are committed to assisting in the development of surveillance and research data required to inform and monitor policy to address the unacceptably high rates of gender-based violence and violence in society more broadly. Mechanisms need to be established to ensure consistency across data sources and to guarantee the quality and utility of official data to serve the prevention agenda. There is a need for an interdisciplinary centre of excellence to assess and validate the utility of different sources of information on violence and to pilot the development of violence observatories or surveillance sites to streamline the collection and process of quality data, both from routine sources and from research surveys.

\section{Declaration. None.}

Acknowledgements. None.

Author contributions. This article expresses the views of authors from several research and disciplinary perspectives. NA was confronted with erroneous reporting of a $117 \%$ increase in female homicide and, with input from DB, requested that GG write to the Statistician-General to ask for the report to be retracted. Following exchanges with other researchers who had queried aspects of the VoCS, RM collated these inputs and drafted the manuscript for an academic audience. RM, NA, BB, NS, MP, SS, DB and GG contributed to the writing of the manuscript; RM, NA, BB, NS, MP, SS, DB and GG: International Committee of Medical Journal Editors criteria for authorship read and met.

RM is deputy-director of the SAMRC's Burden of Disease Research Unit, and principal investigator of the first nationally representative study of injury mortality in SA. NA is director of the SAMRC's Gender and Health Research Unit and principal investigator of two nationally representative female homicide studies. BB is professor of psychology at the School of Human and Community Development, University of the Witwatersrand, and principal investigator of a study that explores the use of robbery data for violence epidemiology. NS is a specialist researcher in the Gender and Health Research Unit and has conducted household surveys on genderbased violence. MP is a senior scientist at the SAMRC's Burden of Disease Research Unit and project manager of the injury mortality study, the basis for her PhD thesis. SS is a lecturer in the Department of Statistical Sciences, University of Cape Town, with expertise in statistical theory and application. He is a co-investigator on the robbery study led by BB and a former member of the SA Statistics Council convened to advise the Minister and the Statistician-General on the production and use of official statistics. DB is director of the SAMRC's Burden of Disease Research Unit, which provides information on the trends in the country's health status and has developed exceptional expertise in summary health measures, health surveys, and mortality data and health informatics analysis, and lead researcher for the SA Demographic and Health Survey. GG is president of the SAMRC, which is constitutionally mandated to improve the health of the country's population through research, development and technology transfer and constantly identifies the main causes of death in South Africa.

Funding. RM, NA, NS, MP, DB and GG are funded by the SAMRC. Conflicts of interest. None.

1. Pillay-van Wyk V, Msemburi W, Laubscher R, et al. Mortality trends and differentials in South Africa from 1997 to 2012: Second National Burden of Disease Study. Lancet Glob Health 2016;4(9):E642-E653. https://doi.org/10.1016/S2214-109X(16)30113-9

2. Abrahams N, Mathews S, Martin LJ, Lombard C, Jewkes R. Intimate partner femicide in South Africa in 1999 and 2009. PLoS Med 2013;10(4):e1001412. https://doi.org/10.1371/journal.pmed.1001412

3. Abrahams N, Jewkes R, Martin LJ, Mathews S, Vetten L, Lombard C. Mortality of women from intimate partner violence in South Africa: A national epidemiological study. Violence Vict 2009;24(4):546-556. https://doi.org/10.1891/0886-6708.24.4.546

1. Jewkes R, Abrahams $\mathrm{N}$. The epidemiology of rape and sexual coercion in South Africa: An overview. Soc Sci Med 2002;55(7):1231-1244. https://doi.org/10.1016/S0277-9536(01)00242-8

2. Machisa M, Jewkes R, Lowe Morna C, Rama K. The war at home: Gender Based Violence Indicators Project, Gauteng Research Report. Johannesburg: Gender Links and South African Medical Research Council, 2011.

3. Norman R, Bradshaw D, Schneider M, et al. Estimating the burden of disease attributable to interpersonal violence in South Africa in 2000. S Afr Med J 2007;97(8):653-656.

4. Mazars C, Magni S, Jewkes R, Shamu S. Study on Violence against Women in South Africa: Know your Epidemic - Know your Response. Pretoria: Department of Women, Children and People with Disabilities, 2013

5. Van Niekerk A, Tonsing S, Seedat M, Jacobs R, Ratele K, McClure R. The invisibility of men in South African violence prevention policy: National prioritization, male vulnerability, and framin prevention. Glob Health Action 2015;8(1):1-10. https://doi.org/10.3402/gha.v8.27649

6. Matzopoulos R, Cornell M, Bowman B, Myers J. 67th WHA Resolution on Violence Prevention misses the mark. Lancet 2014;384(9946):854-855

Matzopoulos R, Bowman B. Sustainable development goals put violence prevention on the map. J Public Health Policy 2016;March:260-262. https://doi.org/10.1057/jphp.2016.13

8. Matzopoulos R, Prinsloo M, Pillay-Van Wyk V, et al. Injury-related mortality in South Africa: A retrospective descriptive study of postmortem investigations. Bull World Health Organ 2015;93(5):303-313. https://doi.org/10.2471/BLT.14.145771

9. Prinsloo M, Bradshaw D, Joubert J, Matzopoulos R, Groenewald P. South Africa’s vital statistics are currently not suitable for monitoring progress towards injury and violence Sustainable Development currently not suitable for monitoring progress towards injury and violence Sustainable Develop
Goals. S Afr Med J 2017;107(6):470-471. https://doi.org/10.7196/SAMJ.2017.v107i6.12464

10. United Nations Office on Drugs and Crime. Crime victim surveys. https://www.unodc.org/unodc/en/ data-and-analysis/Crime-Victims-Survey.html (accessed 26 September 2018).

11. Hirschowitz R, Buwembo P, Serwadda-Luwaga, J, Nasholm H. Victims of Crime Survey. Pretoria: Statistics South Africa, 1998. http://sada-data.nff.ac.za/handle/10956/82 (accessed 28 January 2019). Burton P, du Plessis A, Leggett T, Louw A, Mistry D, van Vuuren
South Africa 2003. Pretoria: Institute for Security Studies, 2004.

South Africa 2003. Pretoria: Institute for Security Studies, 2004.
13. Van Dijk J, van Kesteren J, Smit P. Criminal Victimisation in International Perspective: Key Findings Van Dijk J, van Kesteren J, Smit P. Criminal Victimisation in International Perspective: Key Findings
from the 2004 - 2005 ICVS and EU ICS. Vienna: United Nations Office on Drugs and Crime, 2007:293. from the 2004 - 2005 ICVS and EU ICS. Vienna: United Nations Office on Drugs and Crime, 2007:293.
http://www.unicri.us/documentation_centre/publications/icvs/_pdf_files/ICVS2004_05report.pdf
(accessed 28 January 2019).

14. Statistics South Africa. Victims of Crime Survey: 2016/17. Pretoria: Stats SA, 2017. http://www.statssa. gov.za/publications/P0341/P03412018.pdf (accessed 28 April 2019).

15. Matzopoulos R, Bhalla K, Harrison JE. Homicide. In: Donnelly P, Ward C, eds. Oxford Textbook of Matzopoulos R, Bhalla K, Harrison JE. Homicide. In: Donnelly P, Ward C, eds. Oxford Textbook of
Violence Prevention: Epidemiology, Evidence, and Policy. UK: Oxford University Press, 2015:11-17. Violence Prevention: Epidemiology, Evidence, and Policy. UK: Oxford University Press, 2015:11-17.
16. Institute for Security Studies Crime Hub. National crime statistics listed by category. https://issafrica. Institute for Security Studies Crime Hub. National crime statistics listed by cate
org/crimehub/facts-and-figures/national-crime (accessed 24 September 2018).

org/crimehub/facts-and-figures/national-crime (accessed 24 September 2018).
17. Statistics South Africa. Crime against women in South Africa: An in-depth analysis of the Victims Statistics South Africa. Crime against women in South Africa: An in-depth analysis of the Victims
of Crime Survey data. Crime Statistics Series volume V. Pretoria: Stats SA, 2018:1-27. Report 03-40of Crime Survey data. Crime Statistics Series volume V. Pretoria: Stats SA, 2018:1-27. Report 03-4028. http://www.st

28 January 2019).
18. World Health Organization. Global health estimates 2015: Deaths by cause, age, sex, by country and World Health Organization. Global health estimates 2015: Deaths by cause, age, sex, by country and
by region, 2000 - 2015. 2016. http://apps.who.int/violence-info/homicide (accessed 28 January 2019). by region, $2000-2015.2016$. http://apps.who.int/violence-info/homicide (accessed 28 January 2019).
. South African Police Service. On a Journey to a Safer South Africa: Crime situation in RSA twelve . South African Police Service. On a Journey to a Safer South Africa: Crime situation in RSA twelve
months 01 April 2017 to 31 March 2018. March 2018. https://www.saps.gov.za/services/long_version_ months 01 April 2017 to 31 March 2018. March 2018. https://www.saps.gov
presentation_april_to_march_2017_2018.pdf (accessed 28 January 2019).

presentation_april_to_march_2017_2018.pdf (accessed 28 January 2019).
20. National Department of Health (NDoH), Statistics South Africa (Stats SA), South African Medical National Department of Health (NDoH), Statistics South Africa (Stats SA), South African Medica
Research Council (SAMRC), Inner City Fund. South Africa Demographic and Health Survey 2016 Pretoria: NDoH, 2016. https://www.dhsprogram.com/publications/publication-FR337-DHS-FinalReports.cfm (accessed 28 January 2019).

21. National Department of Health, Medical Research Council, OrcMacro. South Africa Demographic and Health Survey 2003. Pretoria: NDoH, 2007. https://www.dhsprogram.com/what-we-do/survey/ survey-display-242.cfm (accessed 28 January 2019).

22. Bowles, R, Garcia Reyes, M, Garoupa, N. Crime reporting decisions and the costs of crime. Eur J Crim Policy Res 2009;15(4):365-377. https://doi.org/10.1007/s10610-009-9109-8

23. Boateng, F. Crime reporting behavior: Do attitudes toward the police matter? J Interpers Violence 2018;33(18):2891-2916. https://doi.org/10.1177/0886260516632356

24. Bowman B, Kramer S, Salau S, Kotze E, Matzopoulos R. Linking criminal contexts to injury outcomes: Findings and lessons from a national study of robbery in South Africa. Int J Public Health 2018;63(8):977-985. https://doi.org/10.1007/s00038-018-1129-z

25. Statistics South Africa. Exploration of the extent and circumstances surrounding burglary/robbery Pretoria: Stats SA, 2014. http://www.statssa.gov.za/?page_id=1854\&PPN=Report-03-40-02 (accesse 28 January 2019).

26. South African Police Service. Addendum to the SAPS Annual Report: Annual Crime Report 2016/2017. Pretoria: SAPS, 2017. https://www.saps.gov.za/about/stratframework/annual_report/2016_2017/gpw_ crime_stats_2017.pdf (accessed 28 January 2019).

27. Jewkes R, Watts C, Abrahams N, Penn-Kekana L, García-Moreno C. Ethical and methodological issues in conducting research on gender-based violence in Southern Africa. Reprod Health Matters 2000;8(15):93-103. https://doi.org/10.1016/S0968-8080(00)90010-7

28. Jewkes R, Dartnall E, Sikweyiya Y. Ethical and Safety Recommendations for Research on the Perpetration of Sexual Violence. Pretoria: South African Medical Research Council and Sexua Violence Research Initiative. 2012. http://www.svri.org/sites/default/files/attachments/2016-04-13/ EthicalRecommendations.pdf (accessed 28 January 2019).

29. Bower C, Abrahams N. Report on the Development of an Information Management System on Violence Against Women and Children in South Africa. Pretoria: South African Medical Research Council, 2015.

Accepted 25 February 2019 